\title{
Prevalence and correlates of physical and emotional abuse among late adolescents
}

\author{
Bilesha Perera $^{1}$, Truls Østbye ${ }^{2}$, P L Ariyananda ${ }^{3}$ and Erandathi Lelwala ${ }^{4}$ \\ (Index words: adolescent, child abuse, risk factors, behaviour, Sri Lanka)
}

\begin{abstract}
Objectives To estimate the prevalence of physical and emotional abuse reported by late adolescent school children in southern Sri Lanka, and to identify demographic and behavioural correlates of such abuse.

Method A cross-sectional survey was administered to a sample of 1099 male and 1290 female late adolescents, through schools in the southern province. Self-report anonymous questionnaires were used. Study variables included age, gender, body mass index (BMI), socioeconomic status, deliberate self harm, substance use, school absenteeism and family conflicts.
\end{abstract}

Results Of the total, $22.4 \%(n=246)$ of males and $15.7 \%$ $(n=202)$ of females reported having been subjected to physical abuse at least a few times in the 3 months preceding the survey $(p<0.05)$, and $31.3 \%(n=324)$ of males and $25.4 \%(n=328)$ of females reported having been subjected to emotional abuse at least a few times in the 3 months preceding the survey $(p<0.05)$. Logistic regression analyses revealed that school absenteeism, deliberate self-harm, substance use, and family conflict were associated with physical and emotional abuse. Socio-economic status and BMI were not found to be associated with physical and emotional abuse.

Conclusion Physical and emotional abuse are important health issues among late adolescent school children in Sri Lanka. Further research is needed to better understand the causal direction of the associations between physical and emotional abuse experiences, and healthrelated behaviours.

\section{Introduction}

Child and adolescent abuse is a worldwide public health problem [1-3]. Children and adolescents who are abused are at risk of developing a range of behavioural and developmental problems [1]. Types of abuse include physical, verbal, emotional, sexual and neglect. In some countries, more than $25 \%$ of children report having been subjected to one or more of these types of abuse [1]. For example, a national study on child abuse conducted in 13 states in India revealed that $69 \%$ of children aged 5-18 reported having been physically abused at least once, and $44 \%$ reported having been humiliated [4]. In Sri Lanka, a study of 12 year old children in Colombo revealed an association between levels of corporal punishments and psychological maladjustment [5]. Case studies of five children aged between 3-11 years, admitted to a teaching hospital in Sri Lanka revealed that the perpetrators usually were close relatives or adults known to the victims [6]. Conscription of children, a new form of child abuse, has also emerged in Sri Lanka [7].

Although the exact prevalence is not known, findings of these research reports indicate that child abuse is a significant problem in Sri Lanka, and health professionals in the country have highlighted the importance of understanding the gravity of the problem so that it can be prevented or reduced [3, 5-7]. Based on research and other available information such as hospital records of mistreated children, strategies are being developed and implemented by many countries to prevent vulnerable groups, especially infants and pre-school children, from being abused [3, 8-9].

Since young people (aged 15 to 24) are often considered to be healthy and less likely to develop physical or psychological health problems, and because the presence of child abuse is often denied by many countries in Asia [7], the health and health risks related to abuse of this age group is infrequently ignored by the general public, by health care providers and by the health authorities in Sri Lanka. Little is known about abuse and mistreatment experienced by late adolescents and about the long-term negative effects of such experiences in the Sri Lankan context. Late adolescent school children in the country may be at the same or even a higher risk of exposure to physical and emotional abusive experiences compared to young children, as late adolescents have more freedom to move around and therefore have more opportunities for contact with perpetrators in their school and community environment.

${ }^{1}$ Department of Community Medicine, Faculty of Medicine, Galle, Sri Lanka, ${ }^{2}$ Duke University Medical Center, North Carolina, USA, ${ }^{3}$ Department of Medicine, Faculty of Medicine, University of Ruhuna, Galle, Sri Lanka and ${ }^{4}$ Department of Economics, University of Ruhuna, Matara, Sri Lanka.

Correspondence: BP, e-mail: <pperera@indiana.edu>. Received 9 July 2008 and revised version accepted 10 July January 2009. Conflicts of interests: none declared. 
We investigated the three-month prevalence and correlates of physical and emotional abuse reported by a representative sample of children aged 18 and over as a part of a large scale survey on health and health behaviour of advanced-level students in the southern province.

\section{Materials and methods}

A cross-sectional survey design was used. The target population was students aged 18 years or over, in the southern province (Galle, Matara and Hambantota districts). A sample of students was recruited from public schools in the three districts. Two stage cluster sampling, stratified by district, was used to select the students [10] and a minimum of 728 students were targeted from each district. In some schools in Hambantota, a significant proportion of students do not attend classes on a regular basis, thus we were not able to get the required sample size from Hambantota district. Data were collected from 2435 students. After cleaning and consistency-checking, the analysis sample included 2389 students; 971 students from Galle, 739 students from Matara and 679 students from Hambantota. From smaller schools, all advanced level classes (year 12 and year 13) were selected, from larger schools, a maximum of 10 classes were sampled. All students aged 18 or over in the sampled classes were invited to take part in the survey. The sample represented the target population reasonably well, namely late adolescent school children in the southern province. Selfadministered, anonymous questionnaires were used for data collection. The questionnaire contained questions relating to a wide range of health issues pertaining to adolescents.

Child abuse can be defined as "anything which individuals, institutions, or processes do (acts) or fail to do (omissions) which directly or indirectly harms children or damages the prospects of safe and healthy development into adulthood" [11]. Physical abuse occurs whenever someone commits an intentional act that causes physical injury to a child, and the injuries may include bruises, burns, cuts, fractures and organ damage [12]. Emotional abuse occurs when a pattern of psychically destructive behaviour is inflicted by an adult on a child [13]. Various types of potentially relevant physical and emotional abusive events that might be experienced by Sri Lankan children were identified from the literature $[1,3$, $14,15]$ and from discussions with experts in the field (a psychiatrist, a psychologist, two school teachers and a sociologist). Based on this literature survey and opinion obtained from the experts, 12 physical abuse and 8 emotional abuse questions pertaining to experiences that late adolescent school children might have experienced in the recent past were included in the questionnaire. Respondents were asked to indicate whether they were subjected to any of these experiences of abuse in the previous 3 months, and the response categories were 'not at all', 'rarely', 'few times' and 'very often'. The research literature pertaining to abuse suggests that gender, socioeconomic status (SES), obesity, unfit family environment, substance use, poor school performance and psychopathologies are associated with physical and emotional abuse of children $[1,5,14-16]$, and most of these factors were included in the questionnaire. Students who had smoked, or used alcohol or other illegal drugs at least once during their life time were categorised as "yes" to substance use and the rest to "no". School absenteeism was reported as number of days absent from school during the past month. Family conflict was investigated using 7 questions on family relationships and students were categorised into two groups; those reporting moderate to severe disturbances in their families ("yes") and others ("no"). Deliberate self-harm was assessed using one question; During the past 12 months, have you ever tried to harm yourself? Socio-economic status was categorised into three levels based on family income and father's occupation.

The questionnaire was pilot tested on 40 students not part of the main study for comprehensibility and understandability, and thereafter refined. It took approximately 45 minutes to complete the whole questionnaire. The questionnaires were introduced and distributed by a group of 12 trained research assistants (science or arts degree graduates). The respondents completed the questionnaires during normal class period. The respondents' weight and height were also measured in a standardised fashion.

No personal identifiers were collected. Ethical approval for the survey was obtained from the Ethics Review Committee, Faculty of Medicine, Galle and from the Institutional Review Board of Duke University Medical Center, Durham, North Carolina, USA. Permission to conduct the survey in the selected schools was obtained from the Provincial Director of Education, southern province and from the principal of each selected school. Data entry was completed using Microsoft Excel. Statistical package for social sciences (version 15) was used for data analysis.

\section{Results}

Of the 2389 students, 1290 (54\%) were female and $98 \%(n=2349)$ were 18 years of age. The majority were from arts classes $(n=716,30 \%)$ followed by bio science $(n=687,29 \%)$, commerce $(n=569,24 \%)$ and mathematics $(n=407,17 \%)$. Ten students did not report their subject stream. The majority were from the lower $(n=1115,47 \%)$ followed by the middle $(\mathrm{n}=1051,44 \%)$ and the upper $(\mathrm{n}=118,5 \%)$ SES category ( 145 students did not provide adequate information to identify their SES). Of the 2266 participants who had given their weight and height measured during the survey, 769 (34\%) were normal $(18.5<=\mathrm{BMI}<25), 1416(62 \%)$ were underweight $(\mathrm{BMI}<18.5), 67(3 \%)$ were overweight $(25<=\mathrm{BMI}<30)$ and $14(<1 \%)$ were obese $($ BMI $>=30)$. 
Table 1. Reported physical abuse events experienced in the 3 months preceding the survey by gender $(\mathrm{N}=2389)$

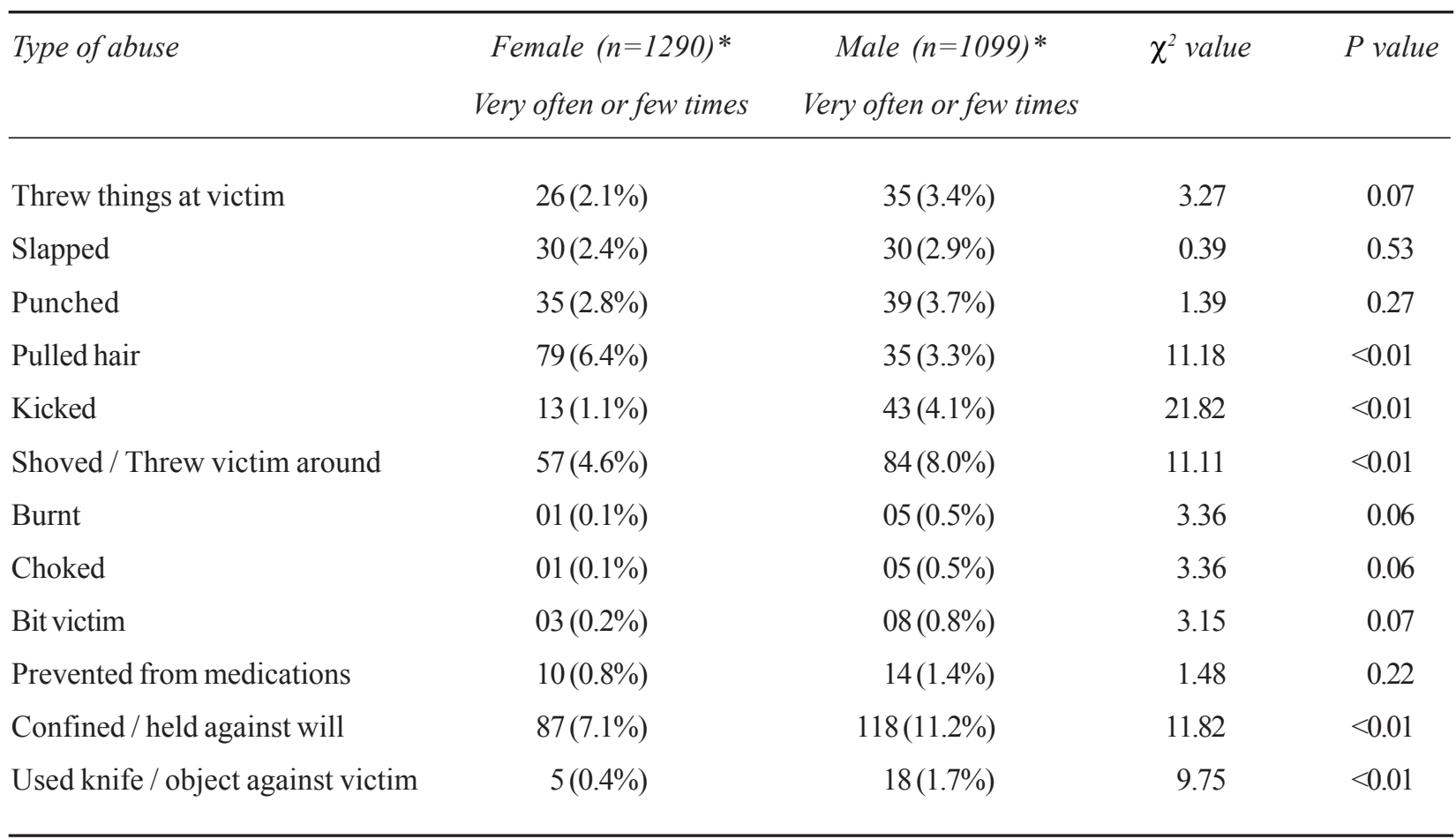

* For some variables the number of responses was slightly less than the total sample

Table 2. Reported emotional abuse events experienced in the 3 months preceding the survey by gender $(\mathrm{N}=2389)$

\begin{tabular}{|c|c|c|c|c|}
\hline \multirow[t]{2}{*}{ Type of abuse } & \multirow{2}{*}{$\begin{array}{c}\text { Female }(n=1290) * \\
\text { Very often or few times }\end{array}$} & \multirow{2}{*}{$\begin{array}{c}\text { Male }(n=1099) * \\
\text { Very often or few times }\end{array}$} & \multirow[t]{2}{*}{$\chi^{2}$ value } & \multirow[t]{2}{*}{$P$ value } \\
\hline & & & & \\
\hline Insulted / humiliated / degraded & $132(10.7 \%)$ & $143(13.6 \%)$ & 4.58 & 0.03 \\
\hline $\begin{array}{l}\text { Intimidated victim through } \\
\text { actions / tone of voice }\end{array}$ & $113(09.2 \%)$ & $120(11.5 \%)$ & 3.19 & 0.07 \\
\hline $\begin{array}{l}\text { Threatened to harm or kill victim / } \\
\text { family member / friend }\end{array}$ & $16(1.3 \%)$ & $31(3.0 \%)$ & 7.81 & $<0.01$ \\
\hline $\begin{array}{l}\text { Threatened to destroy victim's } \\
\text { personal property }\end{array}$ & $10(0.8 \%)$ & $14(1.4 \%)$ & 1.52 & 0.22 \\
\hline $\begin{array}{l}\text { Controlled where victim went / } \\
\text { saw / talked to }\end{array}$ & $149(12.1 \%)$ & $129(12.4 \%)$ & 0.05 & 0.82 \\
\hline Treated victim like a slave / servant & $26(2.1 \%)$ & $27(2.6 \%)$ & 0.57 & 0.44 \\
\hline $\begin{array}{l}\text { Discounted victim's accomplishmen } \\
\text { strengths }\end{array}$ & $93(7.5 \%)$ & $112(10.7 \%)$ & 6.78 & $<0.01$ \\
\hline Interfered with final decisions & $69(5.6 \%)$ & $53(5.1 \%)$ & 0.28 & 0.60 \\
\hline
\end{tabular}

*For some variables the number of responses was slightly less than the total sample 


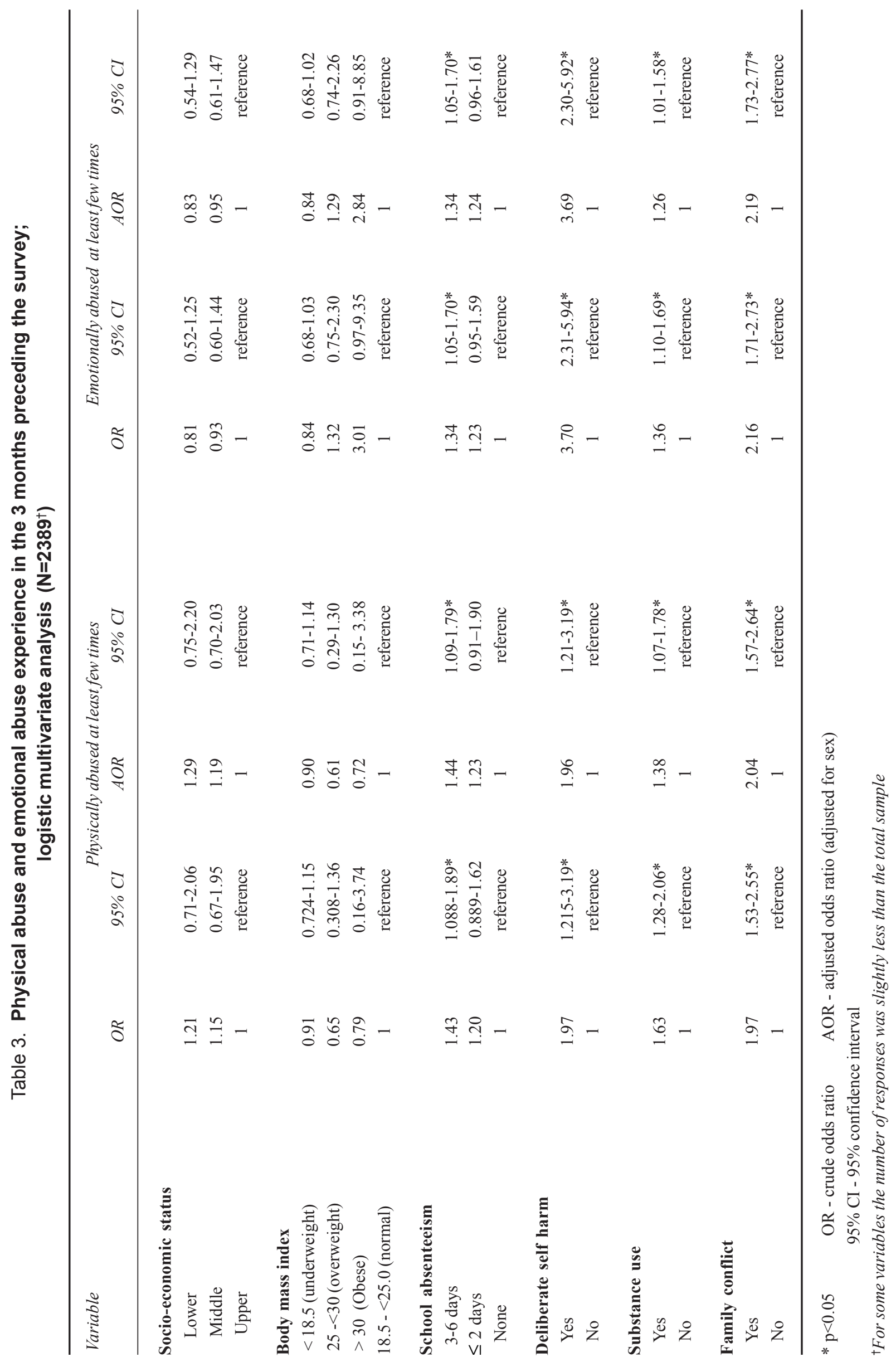


Overall $22.4 \%(n=246)$ of males and $15.7 \%(n=202)$ of females reported having been subjected to at least one type of physical abuse frequently (at least "few times" in the 3 months preceding the survey) $(p<0.01)$. Table 1 shows the percentage of students who reported being subjected to different types of physical abuses frequently. Males were more likely than females to report these different types of abuse. Pulling hair, preventing one from his/her wishful conduct/behaviour and shoving were more common than the other types of physical abuse.

Overall $31.3 \%(n=344)$ of males and $25.4 \%(n=328)$ of females $(\mathrm{p}<0.01)$ reported having been frequently subjected to at least one type of emotional abuse $(\mathrm{p}<0.01)$. Table 2 shows the proportions of students who reported being frequently subjected to different types of emotional abuse. As for physical abuse, males were more likely than females to report emotional abuse. Insulting and/or humiliating, intimidating and controlling one's normal activities were more common than the other types of emotional abuse.

We used multiple logistic regression analyses to investigate the association between abuse experiences and a number of demographic and health related variables including SES, body mass index (BMI), deliberate selfharm, substance use, school absenteeism and family conflict. Results are shown in table 3.

Since students' experience of physical and emotional abuse are gender related, odds ratios were adjusted for sex. No associations were found between abuse experiences and SES and BMI. The more a student was absent from school the higher the odds of physical abuse. Those students who reported having deliberately harmed themselves in the previous year, who had used substances, or who reported unhealthy family relationships were more likely to report physical and emotional abuse.

\section{Discussion}

This study indicates that a considerable proportion of both male (22.4\%) and female (15.7\%) late adolescent school children have been victims of physical abuse, with males reporting higher frequencies of the events studied. In general, our findings are consistent with the findings of a large scale study on child abuse in India in that boys were more likely than girls to be the victims of physical abuse [4], although some studies have demonstrated the opposite, namely that female adolescents are at greater risk of physical abuse compared to males [14]. Logistic regression analysis revealed that neither SES nor BMI was associated with physical abuse in this population. This result contrasts with other research which has linked child abuse to poverty $[4,15]$, and also shown that children outside the narrow weight and shape norms are at a higher risk of physical abuse [16]. The very low percentage of obese children in Sri Lanka may be one of the reasons for this unexpected result, and further research is needed to better understand this finding. The more days a student is absent from school the higher the chances that he or she is subjected to physical abuse: the causal direction of this relationship will also need to be investigated further. As seen in other countries [1, 17], substance use, deliberate self-harm and unhealthy family relationships were all found to be related to physical abuse in this school population.

The prevalence of emotional abuse in this school population is higher than that of physical abuse and again males were at greater risk (31.3\% versus $25.4 \%$ ). Again the gender difference observed in this sample is similar to the findings from the Indian study where $51 \%$ of boys and $49 \%$ of girls were subjected to humiliation by someone. As for physical abuse, school absenteeism, deliberate self-harm, substance use and family conflict were related to emotional abuse, signifying the importance of these four variables as central warning signals for any type of abuse.

We have used a range of measures of abuse in this study, some indicating less serious and others more serious, abuse. However, because of the culture sensitive nature of the variables studied, the prevalence of physical and emotional abuse nevertheless suggests that mistreatment of children and adolescents needs more attention from teachers and physicians, and from health and educational authorities $[11,18]$. The types of abuse that could be considered serious such as being cut or hit with a knife or with an object, being burned or being choked were reported by a considerable number of participants. Since experience of abuse is strongly associated with poor health in later life $[19,20]$, adolescent mistreatment in general, should be considered a serious public health issue in Sri Lanka.

The limitations of this study include the use of selfreport, some missing children from some of the schools (absenteeism is, as we have seen, related to abuse, so our estimates may be conservative) and no adjustment for clustering by school or class. Its strengths include the relatively comprehensive battery of questions relating to physical and psychological abuse, the large catchment area and the large sample size including both boys and girls.

In conclusion, this study shows that a considerable proportion of late adolescents experience physical and emotional abuse, and that even serious abuse is not uncommon. Further research on this topic is needed to better understand temporal relationships between abuse experiences and modifiable behavioural factors such as substance use and family conflicts.

\section{Acknowledgements}

This study was funded by the Tsunami Fund established by the Chancellor of Duke University Medical Centre and by the Hubert Yeargen Centre for Global Health. 


\section{References}

1. Butchart A, Harvey AP, Main M, Furniss T. Preventing child maltreatment: a guide to taking action and generating evidence. World Health organization and International Society for Prevention of Child Abuse and Neglect. Geneva: World Health Organization; 2006.

2. Lampe A. The prevalence of childhood sexual abuse, physical abuse and emotional neglect in Europe. Journal of Psychosomatic Medicine and Psychotherapy 2002; 48: 370-80.

3. De Silva DGH. Some reflections on child abuse in Sri Lanka. Sri Lanka Journal of Child Health 2000; 29:104-6.

4. Ministry of Women and Child Development. Study on Child Abuse - India 2007, Ministry of Women and Child Development, Government of India, New Delhi, 2007.

5. De Zoysa P, Newcombe PA, Rajapakse L. Consequences of parental corporal punishment on 12 year old children in the Colombo district. Ceylon Medical Journal 2008; 53: 7-9.

6. Mahendrarajah V, Rajagopalan L, Wickramasinghe N. Child abuse as seen in the north Colombo teaching hospital. Ceylon Journal of Child Health 1993; 22: 25-6.

7. De Silva DGH. Children needing protection: experience from south Asia. Archives in Diseases in Childhood 2007; 92: 931-4.

8. Copeland JB. School intervention programmes: an approach to preventing child abuse. New Jersey Medicine 1995; 92: $104-6$

9. Duggan A, McFarlane E, Fuddy L, Burrell L, Higman SM, Windham A, et al. Randomized trial of statewide home visiting programme: impact in preventing child abuse and neglect. Child Abuse and Neglect 2004; 28: 597-622.

10. Bennett S, Woods T, Liyanage WM, Smith DL. A simplified general method for cluster sample surveys of health in developing countries. World Health Statistics Quarterly 1991; 44: 98-106.
11. De Silva DGH, Hobbs C. Child abuse: a manual for medical officers in Sri Lanka, The National Child Protection Authority of Sri Lanka, Colombo, 2000.

12. Rodriguez-Srednicki O, Twaite JA. Understanding and reporting child abuse: legal and psychological perspectives: part 1: physical abuse, sexual abuse and neglect. The Journal of Psychiatry and Law 2004; 32: 315-59.

13. Rodriguez-Srednicki O, Twaite JA. Understanding and reporting child abuse: legal and psychological perspectives: part 2: physical abuse, sexual abuse and neglect. The Journal of Psychiatry and Law 2004; 32: 443-81.

14. Silverman AB, Reinherz HZ, Giaconia RM. The long-term sequelae of child and adolescent abuse: a longitudinal community study. Child Abuse and Neglect 1996; 20: 709-23.

15. U.S. Department of Health and Human Services. National Centre on Child Abuse and Neglect. The third national incidence study of child abuse and neglect, 1996, 2-17.

16. Whitaker RC, Philips SM, Orzol SM, Burdette HL. The association between maltreatment and obesity among preschool children. Child Abuse and Neglect 2007; 31: 1187-99.

17. Arata CM, Langhinrichsen JR, Bowers D, O'Brien. Differential correlates of multi-type maltreatment among urban youth. Child Abuse and Neglect 2007; 31: 393-415.

18. De Silva SG. Child abuse. Ceylon Journal of Child Health 1993; 22: 1-2.

19. Wijma K, Samelius L, Wingren G, Wijma B. The association between ill-health and abuse: a cross-sectional population based study. Scandinavian Journal of Psychology 2007; 48: 567-75.

20. Haugaad JJ. Recognizing and treating uncommon behavioural and emotional disorders in children and adolescents who have been severely maltreated: introduction. Child Maltreatment 2003; 9: 123-30. 